International Journal of English Literature and Social Sciences
Vol-6, Issue-3; May-Jun, 2021
Journal Home Page Available: https://ijels.com/
Journal DOI: $10.22161 /$ ijels

Peer-Reviewed Journal

\title{
The Art of Uncertainty: A Scrutiny in Theatre of Michael Frayn
}

\author{
Mohammadi, Midia
}

MA in English Literature, University of Tehran, Iran.

Received: 02 Apr 2021; Received in revised form: 03 May 2021; Accepted: 28 May 2021; Available online: 11 Jun 2021 (C)2021 The Author(s). Published by Infogain Publication. This is an open access article under the CC BY license (https://creativecommons.org/licenses/by/4.0/).

\begin{abstract}
The central idea upon which plays of Micheal Frayn are established is that a text or event is reborn and reconstructed every time it is recited or recalled. He sublimated history, physics, and various dramatic techniques into splendid drama to reflect upon the dilemmas thrown to the human in today's world of indeterminacy. It will be explored how Frayn has plied 'uncertainty principle' to drama with a distance from Becket and Brecht by analyzing three plays. Furthermore, his expressed perspective on the Brechtian notion of the 'alienation effect' is discussed. The plays chosen for this article areNoises Off (1982), Audience (1991), and Copenhagen (1998).
\end{abstract}

Keywords-Uncertainty, Interdisciplinary Study, Textual Fluidity, Micheal Frayn.

\section{INTRODUCTION}

Modern physics came to the twentieth century as a shock with declaring relativity and the 'uncertainty principle.' It was not surprising that the nihilism absorbed the indeterminacy as in its bosoms to expose the futility of life, and playwrights like Beckett plied that notion to life, drama, and more importantly, to self. While modern physics continued shattering the deeply ingrained previous ideas in the human mind, the paralyzing gloom of the twentieth century remained in the past, and as writers moved toward the twenty-first century, they kept the uncertainty of life with them but repelled the despair surrounding it. The difference came from experience. Despite the long path of civilization that the twentiethcentury man took, he was still too naive and could not make peace with all the disastrous events shattering all his ideas. The twenty-first-century authors were not as angry as their previous generations; they had accepted the new world's ways and made their peace with the uncertainty in life. Among the ashes of the Beckettian paralysis of modern man and the Brechtian call for political activism through plying the 'alienation effect,' a Fraynian phoenix emerged, which had absorbed both of them. Frayn's works reflected the indeterminacy yet did not find it repulsive or dark.
Michael Frayn, the English novelist, and playwright who has studied moral science at Cambridge, has earned a reputation for writing various plays and novels in different styles and genres. While Frayn's techniques are not so novel in essence, he has made idiosyncratic alterations to the concepts. He regards drama as a live entity that shapes itself in every performance or rehearsal since the texts or events cannot be definite and are born every time they are recited or recalled. He once stated in an interview on philosophy and writing that "a lot of characters in plays don't understand themselves - this is their problem." 'The statement expresses how he believes in the 'uncertainty principle' that conforms to character fluidity that runs subtly throughout his work. He believes that no play would exist without the audience, and it would be impossible to have a fixed performance since people and characters are made of subatomic particles, which due to Heisenberg's 'uncertainty principle,' would never be fixed or predictable. However, Frayn does not regard uncertainty as a tragic element in modern man's life but finds an opportunity to make entertaining comedy out of the fact. Frayn is famous for expressing the most profound philosophical thoughts in his comedies. Noises Off (1982), was written and constructed upon the notion that the performance is never fixed. Later, Frayn took it further in 
Audience (1991) by implying that not only the performance but even the text changes every time it is read. He also added the idea that there would be no play without the audience where he adopted the Saussurian notion that the "sign" and "signified" have an arbitrary relationship. He takes drama and performance to a subjective stance where the audience, as well as the drama group, are responsible for the production of a play or, to be more accurate, for the play to exist. In one of his most celebrated plays,Copenhagen (1998), he affirms that not only a play but also an event in life cannot be accurately recalled even by the ones who were a part of that in the beginning. In this celebrated historical play, Bohr and Heisenberg, the fathers of 'uncertainty, try to recall an event in 1941, and they can never finally reach a consensus.

\section{SCIENCE AND LITERATURE}

Science and literature, experiments and imagination, have walked hand in hand in a dialogical process for centuries. Since the emergence of empiricism in seventeenth-century England and the creation of new sciencebased on experiments, many texts have applied human's accurate knowledge to literary works, and many of them have foretold new technologies to come. While science and technology landed the first man on the moon finally in the twentieth century, reaching the moon and discovering new colonies of creatures on other planets was not far from the imagination of scientists such as Joannes Kepler (15711630) and writers like Bishop Francis Godwin (15621633). Kepler's Somnium (=The Dream), which was published posthumously in 1634 , sent him to the moon to find habitants there and Godwin's the Man in the Moone (1638) explored a voyage to the moon and affirmed the idea of extra-terrestrial life. Literature and science change the world and push it towards progression while they affect and influence each other as well as the economic, social, and political structures. The influence of modern physics and 'uncertainty principle' on art and drama in the twentieth century is nevertheless an outcome of the era's radical scientific and political changes. In the 'Postscript of Copenhagen' (1998), Frayn states:

What the uncertainty of thoughts does have in common with the uncertainty of particles is that the difficulty is not just a practical one, but a systematic limitation which cannot even in theory be circumvented. It is patently not resolved by the efforts of psychologists and psychoanalysts, and it will not be resolved by neurologists, either, even when everything is known about the structure and workings of the brain, any more than semantic questions can be resolved by looking at the machine code of a computer. And since, according to the so-called 'Copenhagen Interpretation' of quantum mechanics - the interconnected set of theories that was developed by Heisenberg, Bohr, and others in the twenties - the whole possibility of saying or thinking anything about the world, even the most apparently objective, abstract aspects of it studied by the natural sciences, depends upon human observation, and is subject to the limitations which the human mind imposes, this uncertainty in our thinking is also fundamental to the nature of the world.

As stated by Heisenberg in the preface of Physics and Beyond (1969), 'Modern atomic physics has thrown fresh light on basic philosophical, ethical and political problems.' In order to speculate the influence of the 'uncertainty principle' on art and drama in the twentiethcentury, it would be necessary to explain it briefly. It would also be essential to see how different playwrights plied the principle in their idiosyncratic ways. Britannica has defined the 'uncertainty principle' as the indeterminacy in citing the position and velocity of a particle or object even in theory. In simpler words, if we know a particle and its behaviour well enough, the calculations will show us some probabilities for where things are situated and how they will behave. There is no way to precisely calculate the particle's position or velocity, and ironically, the more accurately we measure one of these values, the less we know the other. Quantum uncertainty aided Derrida in shattering the transcendental signified and contributed to deconstructive approaches that attempted to eliminate the discriminative binary oppositions. Derrida assumes that a 'cloud of virtual alternate signs' (Argyros, 36) are around every word. These virtual elements can 'pop into existence at any moment in the reader's mind'(36); therefore, the stability of the text becomes a myth. Before quantum physics, the fundamental forces had provided studies with a decidable background. Thus, quantum uncertainty leads postmodern and poststructural thinkers to capture the world as a flux of signs and elements that cannot be determined or interpreted.

Another theory that contributed to the uncertainty is the 'principle of complementarity' established by Bohr, which states that the behaviour of such phenomena as light and electrons, is sometimes wavelike and sometimes particle-like (Britannica) that can lead to duality. More interestingly, such particle and wave characteristics in the 
same large-scale phenomenon are incompatible rather than complementary. This could also be regarded in two ways: First, it is a complication of another complicated principle which is very much like the modern world in the twentieth century. Second, as Heisenberg states in Copenhagen, taking this principle into account, it would be impossible to know human behaviour:

'We can't completely understand your behaviour without seeing it both ways at once, and that's impossible, because the two ways are mutually incompatible.'

Frayn has not acquiesced in using only these two principles to depict the uncertainty but has also touched upon the famous Schrodinger's wave formulation, which has become the emblem for uncertainty in common culture. Schrodinger is widely known for his 'Schrödinger's cat.' While Erwin Schrödinger published his equation prior to Heisenberg's 'uncertainty principle' and Heisenberg was not fond of him because Schrödinger had said that his mathematics was repulsive, it is publicly known to be a source of uncertainty in real life, and it is necessary to be briefly elaborated. Since the aim of this article is far from delving into physics and Schrödinger's equation differs from Heisenberg's, instead of explaining the equation, it would be more efficient to elucidate 'Schrödinger's cat' which came to existence in 1935 and is a simplified representation of his thoughts. Schrödinger wanted people to imagine that a cat, poison, a Geiger counter, radioactive material, and a hammer were inside a sealed container. The amount of radioactive material was minuscule enough that it only had a fifty percent chance of being detected over the course of an hour. If the Geiger counter detected radiation, the hammer would smash the poison, killing the cat. Until someone opened the container and observed the system, it was impossible to predict if the cat's outcome. Thus, until the system collapsed into one configuration, the cat would exist in a position being both alive and dead. What Schrödinger was trying to prove and simplify was that the indeterminacy of sub-particles. He also pointed to flaws in Copenhagen's interpretation. Nevertheless, this hypothetical experiment has remained a popular source for explaining the haziness in the universe and applying it to human behaviour; it would be again impossible to fully and precisely understand the human mind since it is a closed box.

One of the most prominent figures to adopt the uncertainty principle was Samuel Beckett, whose original plays revolutionised the Theatre of Absurd. He mostly applies the uncertainty principle in a more psychological manner which differs from Frayn's situational uncertainty. According to Uhlmann in After Beckett (2004), this uncertainty is found when the unnamed protagonist of The Unnamable (1958)cannot locate an "I." To analyse this, Uhlmann puts the words in "Bohr's notion of complementarity and/or Heisenberg's Uncertainty Principle" (47) and concludes that "one cannot be conscious of being unconscious." Beckett's most use of the principle can be found in his drama as well as his fiction, and this can be traced in his most notable works such as Waiting for Godot (1954), Endgame (1957), and Not I (1971). The characters of his drama are hopeless and fully aware of being stuck in the uncertainty, finally resolved in a certain situation, their death. Beckett and Frayn share an affinity in believing that the play must mean what it means. This "anti-criticism" (Uhlmann, 279) attitude that was majorly an issue after Beckett's resistance to revealing the meaning of his famous Waiting for Godot, lead many other playwrights to create drama that was meant to be felt rather than pondered. Despite their affinity in the attitude, these two playwrights take two completely different paths in making their point.

While Beckett's uncertainty produces plays full of anxiety, Frayn convinces the audience that this is a typical situation in life that can be regarded through its comic effect. In Noises Off, a play within a play, the plot is wholly abandoned and altered by the actors on stage, the performances are poor, and the play seems entirely changed and transformed into another one. Frayn regards the text of a play as only one of the elements in its production and insists on receiving the notion of theatre as an alloy made of many particles. He embraces the uncertainty of life and applies it to performing a play. The outcome is surely not what the director and the drama group expected but brings laughter to the audience. His brilliance shows face in standing against advocates of nihilism who portray the new world as a dark, gloomy flux of uncertain data.

Frayn establishes the serious idea of 'textual fluidity' in the most comic tone to express his most pressing concern. As stated by Frayn, the paradoxical dilemma lies in the fact that a text exists even if it does not find a reader while its existence is dependent on its reader. This notion of 'textual fluidity' and whether a text exists without being perceived is again recalled in Audience (1991). Considering different texts and dividing them into the categories suggested by Roland Barthes in S/Z (1970), some texts are 'scriptible' or 'writerly' and some are 'lisible' or 'readerly'. Frayn strongly believes that every drama piece is a 'readerly' text that is reborn with every reading and altered every time it is performed. Frayn applies this not only to the play but regards every modern phenomenon to be 'readerly,' and he believes that the play's final production is completed in the minds of the 
audience who perceive it differently and subjectively. More importantly, he asserts that this subjectivity is rather fluid in its essence and while the signs seem fixed, nothing they convey or perceived through them can be fixed or repetitive.

I suspect that usually the situation comes first. I think often, as with evolution, the best ideas are really quite simple ones, and do reflect some real possibility in the world. The element of play is very important in literature and is often forgotten about because people think that literature should have some serious purpose. But one of the things about the theatre, and fiction, is that you can play. You can actually investigate situations that don't exist, and you're not bound by the actuality of the world. ${ }^{\text {ii }}$

Noises Off asserts that every drama group adds its own spice to the recipe provided for them by the playwright. Since a play is performed by actors who are people, their lives, mentalities, and feelings impact the final production. Nevertheless, the play is produced one more time in each performance as the director and actors bring their own ideas and lives into the script. Frayn explains in Stage Directions (2008) that the actors in Noises Off are haunted by the fear of losing the order they have gained in time through hard labour.Frayn's subtile message in his works expressed that modern man must accept the inherent uncertainty in life rather than fighting it. Noises Offdepicts how hard it is to construct order and how that final order can easily fall into chaos by the smallest particles of the system. In Stage Directions, Frayn acknoweldges that the dilemma which occupies his mind is not an original one and has been the concern of philosophers for two millenniums and will continue to confuse minds for another two thousand years:

The dilemma is this: the world plainly exists independently of us - and yet it equally plainly exists only through our consciousness of it. We are circumstantial specks, insignificant local anomalies, amidst the vast structured fabric of the objective universe. And yet that universe has vastness only in relation to ourselves and the things around us - has structure only in so far as we give it expression in our perception and languagehas objective form only in so far as we conceive it from our single standpoint in space and time. We are everything and nothing. We are responsible for everything, and responsible for nothing. (10)
Beckett's characters are not responsible for anything; they are stuck in a situation and paralyzed while Frayn gives them choices and lets them mobility throughout the play. His work is philosophical yet in a grotesque combination with comedy, its final product entertains the audience rather than pushing them into the uncomfortable sense of indeterminacy.

Audience, a one-act comedy about theatre as a phenomenon, lets the audience and the actors work together consciously and unconsciously. Frayn has used a plot that breaks the fourth wall without literally breaking it and has thought of facing the audience with another group of actor-audience, which is like holding a mirror to the real ones. The subjectivity of drama as a phenomenon is explored through various attitudes of different characters, and it is depicted on a spectrum from the always sleeping Merill, who does not seem to know where he is, to Quentin, an attentive drama expert. Keith, the playwright, is terribly disturbed by the fact that his efforts are going to waste by the inattentiveness of people. He speaks for Frayn and every playwright when he expresses through his words and actions that the play would not exist if not perceived by the audience. Furthermore, Keith's anger asserts that a playwright's task is not finalised with putting the words in black and white, and every time a play is performed, it is revived and affects its creator since the text is a part of him/her, never wholly detached. Why is a creator always curious about the reaction of the readers, audience, or critics, consumers of the product if his/her job was done by preparing the final product?

The charge builds and builds before the lightning strikes; and the particles in which the electricity is stored are the audience. I sometimes feel that the skill of audiences is not always sufficiently noted... To find two, or five, or ten good actors to perform a play is difficult; to find two hundred, or five hundred, or a thousand good people to watch it, night after night, is a miracle. So many people in one room who will sit quietly and listen for two hours - not calling out slogans, not breaking down under the strain of so much communal self-discipline! To be a member of a good audience is exhilarating. The sounds that it makes around you are as much a part of the show as the sounds from the stage: the sound of alert anticipation before the curtain rises - the sound of silence - the sound of implications being understood - the sound of generosity in laughter and response. ${ }^{\text {ii }}$ 
Frayn not also uses words to express what he has in mind but also uses pauses and silences as a way to create the effect he intends to in the manner of 'Pinter Pause' and 'Pinter Silence' established by Harold Pinter. His characterisation relies primarily on each characters' discourse to show their mindsets. Characters, not surprisingly, are lost in their own subjective worlds, and as they respond to each other, in an absurd sense, it seems that they do not comprehend what the other one is saying; therefore, there exists a flow of words that do not lead to communication. The idea of subjectivity runs through the play from the beginning, as all these people are seated in one place to see one single play when it comes to perceiving the play- or more generally, the world- they have nothing in common, and they perceive it according to their own mindset. The questions that are left with no responses and the repetition of some sentences and phrases create a sense of communication stalemate as well as creating verbal humour. Helena is sorrowful, and despite all the easily perceived signs, her mother, Joan, has no idea about her discomfort. The couples do not understand each other, and Quentin does not comprehend Lee's questions or his fondness for Wendy at all. Furthermore, Keith is ironically totally negligent about his audience even though he had stated that all his effort was to write something that people could enjoy and identify with.

Besides using different techniques of Absurd Theatre in dialogues or Pinter's pauses and silences, the play is at root very Brechtian in the sense that its plot is an emblem of alienating the audience while ironically and paradoxically engaging them in the production. The audience encounters some other people seated in an auditorium watching them and pretending that they see everything, and ironically, Frayn has taken it into account that it does not necessarily evoke contemplation. When the characters see a man putting his hand on the lady's knee, which is precisely the image provided by Charles and Amanda, they do not have the sense that they are the ones discussed. The play gives the audience a sense of selfconsciousness that does not necessarily drag them into pondering if prevented from having "emotional spasm," as Keith put it.

It is not only in this play that Frayn mocks 'the alienation effect.' While the principle aims to provoke a socialtheatrical response by making the familiar strange', Frayn challenges the idea as he is trying to state that no play can be thought-provoking unless the audience intends to take an active role in perceiving it thoroughly. The characters see many images in the hypothetical play that are reflections of themselves, but they are not necessarily aware of their own surroundings; therefore, they cannot ponder the situation. The same things happen for the actual audience who is facing a very Brechtian play and is laughing instead of taking Keith's criticism of the audience into account

Copenhagen is a historical drama in two acts constructed on one foundation, a simple question that is "Why did Heisenberg come to Copenhagen in 1941?" Based on a historical event, Frayn is disinterring the long lost mystery of Heisenberg's visit to Copenhagen in 1941. The spirits of Werner Heisenberg, his colleague and mentor, Neils Bohr and his wife, Margrethe, meet to find an answer to this question. Bohr and Heisenberg discuss the possibility of different versions of their meeting. While 'World War II' was still ongoing, and Germany had invaded Denmark despite a nonaggression agreement between the two countries, the meeting of the two scientists was both dangerous and awkward. Bohr was an esteemed nuclear physicist in Denmark and had served as Heisenberg's mentor. The play explores the two scientists' professional relationship and reflects their historic contributions to physics as well as giving us a sense of uncertainty in narration. It ends without resolving the initial question.

Frayn is the most brilliant for choosing Niels Bohr and Werner Heisenberg as his characters for the play since there could be no better alternative characters in accordance to the theme of the uncertainty of life than the theorists who created that. Robert Oppenheimer (19041967), the American theoretical physicist who was the director of the Manhattan project, called Bohr 'the team's father-confessor' and Heisenberg was the man who not only formulated the 'uncertainty principle' but also believed that 'science is rooted in conversations.'

Heisenberg was the son of the only ordinarius professor of medieval and Modern Greek studies in Germany. He had tipped his toe in Plato and many classical works since childhood which had created in him an interest in arts besides his profound scientific studies. He met Bohr for the first time in Bohr Festival in 1922. They laid the foundation of their friendship that was firmly constructed in 1924 when Heisenberg went to do research with him at the University of Copenhagen. It was there in Copenhagen that Heisenberg developed his famous 'uncertainty principle' while working on the mathematical foundations of quantum mechanics. Frayn states that he is not very fond of the word 'uncertainty' in his postscript on the play and suggests several alternatives for it; however, to prevent any confusion, the words "indeterminacy" and "uncertainty" are used in this article interchangeably.

'Uncertainty' is not a very satisfactory word to come at this. It sits awkwardly even in its original context. You can be uncertain 
about things which are themselves entirely definite, and about which you could be entirely certain if you were simply better informed. Indeed, the very idea of uncertainty seems to imply the possibility of certainty. Heisenberg and Bohr used several different German words in different contexts. Bohr (who spoke more or less perfect German) sometimes referred to Unsicherheit, which means quite simply unsureness. In Heisenberg's original paper he talks about Ungenauigkeit - inexactness - and the most usual term now in German seems to be Unschärfe-blurredness or fuzziness. But the word he adopts in his general conclusion, and which he uses when he refers back to the period later in his memoirs, is Unbestimmtheit, for which it's harder to find a satisfactory English equivalent. Although it means uncertainty in the sense of vagueness, it's plainly derived from bestimmen, to determine or to ascertain. This is reflected better in the other English translation which is sometimes used, but which seems to be less familiar: indeterminacy. 'Undeterminedness' would be closer still, though clumsy. Less close to the German, but even closer to the reality of the situation, would be 'indeterminability'. iv

Since Copenhagen was expected to be produced on the radio, Frayn did not put much time in arranging the setting or direction for the characters' actions, which put the whole burden of the plot on its dialogues. Frayn thought of his play as "boring and abstract" and unsure if anyone would produce it. (Michael Frayn in an interview with Macry Kahan, BOMB, No. 73) Copenhagen is undoubtedly not dull in the sense of exploring many modern elements disguised in the simple colloquial language of everyday conversations. Language in postmodern drama became a concealing device rather than a means of conveying meaning. As quantum mechanics was shattering the firmly established Newtonian rules, the theories in the language domain were also going under a grave alteration. Thus, language and words were no more manipulative devices trying to systematise a fragmented world that could no longer be seen as an organised linear system.

Heisenberg: 'If it works it works.' Never mind what it means.

Bohr: Of course I mind what it means.

Heisenberg: What it means in language.
Bohr: In plain language, yes.

Heisenberg: What something means is what it means in mathematics.

Bohr: You think that so long as the mathematics works out, the sense doesn't matter.

Heisenberg: Mathematics is sense! That's what sense is!

Bohr: But in the end, in the end, remember, we have to be able to explain it all to Margrethe!

Margrethe: Explain it to me? You couldn't even explain it to each other! You went on arguing into the small hours every night! You both got so angry!

Bohr: We also both got completely exhausted.

The irony of Copenhagen's indeterminacy is in the haziness of the reason for that. One cannot determine if it is only the uncertainty principle illuminated in the play or the different perspectives of characters or the inadequacy of language and incompatibility 'ecological time', 'historical time' and 'cosmological time' as Paul Smethurst puts it in The Postmodern Chronotope (2000). The language inadequacy and the spirits of the three characters lost in time are definitely adding to the vagueness of the discussion, and the effort they put into answering the question is anendeavour of modern man to rationalise the past and find meaning in a world where language, time and history do not exist in their old fashioned sense anymore. Heisenberg himself is aware that language and the human condition cannot be put in a system by using mathematics. He believes that the meaning in language is lost and can only be found in mathematics, and he states it by saying: 'mathematics becomes very odd when you apply it to people. One plus one can add up to so many different sums.' However, he cannot find meaning anywhere else, so he resides in mathematical, logical explanations.

On the other hand, Bohr pragmatically tries to find an answer using any theory or speculation. He states that they would have to see it from two different and divergent aspects to reach a solution, which implies that they would never reach a conclusion. Heisenberg's certainty through the play as a man famously known as the father of uncertainty indicates the irony strongly. Heisenberg states that people are 'simultaneously alive and dead in our memories.' And that 'How difficult it is to see even what's in front of one's eyes. All we possess is the present, and the present endlessly dissolves into the past.' 
Yet, he continues to argue that they have to be certain, that he declines paradoxes and contradictions while he is obviously the primary source of them. Bohr responds to him, which has been put in the best choice of words by Frayn:

'You live and breathe paradox and contradiction, but you can no more see the beauty of them than the fish can see the beauty of water.'

As Robert L. King has stated it in The Play of Uncertain Ideas, Copenhagen stands in the Beckettian tradition of Waiting for Godot (1953). He correctly believes Heisenberg and Bohr to be the heirs of Vladimir and Estragon, 'but they do not play roles to pass the empty time merely; rather, along with Margrethe, they play them as re-enactments of actual events, as present recreations of discussions and their historical contexts.' Furthermore, he finds traces of Brecht alongside Beckett in Copenhagen when the characters try to reconstruct the scene to reach the answer. Once again, as mentioned in the close reading of Audience, Frayn shows his disagreement with the Brechtian notion of drama which aims to provoke the audience to rational contemplation and social awareness. The more we proceed through the play, the less we understand the answer to the fundamental question posed in the beginning. The plot and dialogues complicate the complex situation, and although the play ends in no conclusion, it has filled the audience with intellectual excitement and the emotional burden of uncertain knowledge. Even when at times the play can go into a Brechtian one, touching upon a moral issue, Frayn refrains from going any further, like when Heisenberg says: 'I chose my words very carefully. I simply asked you if as a physicist one had the moral right to work on the practical exploitation of atomic energy.' Bohr's response to that stops the play falling into that trap: 'I can't recall.'

Heisenberg's findings "undermines empiricism when we learn that we never can fully trust sensory evidence in observing physical reality." (Rabinovitz, 42) Beckett's assumption differs from Frayn's in perspective for its reflection of uncertainty as a dark fact of modern man's life. In Frayn's mindset, this does not lead to pessimism. Beckett finds this uncertainty rapidly unnaming everything and takes away the identity from his characters. On the other hand, Frayn applies this to a bigger picture of life in general and does not dismantle the 'self.'

\section{CONCLUSION}

While modern life seemed shattered and chaotic in the aftermath of the disastrous eruptive events in the twentieth century, life in the postmodern era as a continuation of its precedent century has nevertheless followed the same path in being indeterminate, unpredictable, and uncertain. Neither life and uttered words nor written down or carved on emblems carry the same meaning twice. Life is fluid as the literary texts are; they cannot be separated and open to different interpretations since both are 'readerly' phenomena that paradoxically exist objectively but cannot exist if not perceived by subjective minds. Michael Frayn has indicated this uncertainty both in the content and form of his plays. His intelligently depicted world of drama is an expression of life in its purest form. It is an amalgam of different classical, modern theories that reflect all the dilemmas haunting men. The ironies and paradoxes in Frayn's drama derive from the unresolved ones existing in real life. His drama expresses how fragile our thoughts and words are and how absurd it would be to rely on them lifelong since neither life nor the human psyche is a fixed state. Although the plays written by Frayn do not necessarily end in resolution, the most crucial conclusion based on them is accepting the uncertainty as a part of life and living happily ever after with that.

\section{REFERENCES}

[1] Ackerley, Chris. "THE UNCERTAINTY OF SELF: Samuel Beckett and the Location of the Voice." Samuel Beckett Today / Aujourd'hui, vol. 14, 2004, pp. 39-51. www.jstor.org/stable/25781455.

[2] Argyros, Alexander. "Deconstruction, Quantum Uncertainty, and the Place of Literature." Modern Language Studies, vol. 20, no. 4, 1990, pp. 33-39. JSTOR, www.jstor.org/stable/3195059.

[3] Bang, Lars. Between the Cat and the Principle. 2014. Power and Education, Volume 6 Number 1

[4] Frayn, Michael. Copenhagen, Anchor Books, a division of Random House, Inc., New York. 2000.

[5] Frayn, Michael. Noises Off. Samuel French, Inc.

[6] Frayn, Michael. Stage Directions: Writing on Theatre 1970-2008. Faber and Faber Limited Bloomsbury House, London. 2008

[7] Frayn, Michael. The Crimson Hotel and Audience. Electronic file by Bloomsbury Methuen Drama, 2016.

[8] Gipson-King, Jay M. The Politics of Time in Recent English History Plays. 2010. PhD Thesis, Florida State University.

[9] Kahan, Marcy. Frayn, Michael. "Michael Frayn". BOMB, No. 73 (Fall, 2000), pp. 54-59

[10] King, Robert L. "The Play of Uncertain Ideas". The Massachusetts Review, Vol. 42, No. 2 (Summer, 2001), pp. 165-175

[11] Heisenberg, Werner. Physics and Beyond. 1971, Harper and Row. 
[12] Lindley, David. Uncertainty: Einstein, Heisenberg, Bohr, and the Struggle for the Soul of Science. Anchor Books, 2008.

[13] Rabinovitz, Rubin. "Time, Space, and Verisimilitude in Samuel Beckett's Fiction.” Journal of Beckett Studies, no. 2, 1977, pp. 40-46. JSTOR, www.jstor.org/stable/44783093.

[14] Ruddick, Nick. 'The Search for a Quantum Ethics: Michael Frayn's "Copenhagen" and Other Recent British Science Plays." Journal of the Fantastic in the Arts, Vol. 11, No. 4 (44) (2001), pp. 415-431

[15] Shrodinger, Erwin. What is life? The Physical Aspect of the Living Cell. Based on lectures delivered under the auspices of the Dublin Institute for Advanced Studies at Trinity College, Dublin, in February 1943. First published 1944.

[16] Uhlmann, Anthony. After Beckett =: D'après Beckett. Amsterdam: Rodopi, 2004. Print.

\section{Endnotes}

'The fundamental paradox: Michael Frayn and A.C.

Grayling on philosophy and writing.

i"Michael Frayn in an interview with Macry Kahan, BOMB,

No. 73

iii Michael Frayn, Stage Directions: Writing on

Theatre(1970-2008)

ivMichael Frayn, 'Postscript of Copenhagen' (1998) 